\title{
移動磁界型磁気探傷装置
}

\section{Moving Magnetic Sensor for Non-Destructive Testing}

\author{
榎園正人・槌田雄二・片井哲也 \\ 大分大学工学部電気電子工学科, 大分市旦野原 700 (-E870-11)
}

M. Enokizono, Y. Tsuchida, and T. Katai

Department of Electrical and Electronic Engineering, Faculty of Engineering, Oita University, 700 Dannoharu, Oita 870-11

This paper describes a new non-destructive testing instrument that searches for defects on the steel surface opposite that into which H-coil and the exciting coil are built. Defects can be found with the $\mathrm{H}$-coil by measuring changes in the eddy current. In this case, defects on the surface of the steel can be found according to the skin depth of the eddy current. Therefore, a moving magnetic field is effective for defects on the opposite surface of the steel, because much information is derived from the moving magnetic field in comparison with an alternative magnetic field. The shape and structure are also important to improve the sensibility of the testing instrument. In this paper, we present some results obtained with our new non-destructive testing instrument, and discuss the possibility of detecting defects in the opposite surface and subsurface region of the steel.

Key words: non-destructive testing, moving magnetic field, opposite surface defects, H-coil, defect depth, defect width

\section{1.はじめに}

金属構造物や発電所の熱交換器配管などに生じた欠陥の検出 には，高速で確度の高い非破壊検査技術が要求されてきた。そ の検查技術の一つとして, 渦電流探傷法 (ECT, Eddy Current Testing）がある11,2!. 同手法により表面上の久陷・傷を検知す るには，高周波励磁を行うためのコイルを，被探傷物に近接さ せ，被探傷物における誘起電王の変化を，サーチコイルにより 湘定する.このとき被探傷物に欠陥があると洞電流の流路が変 化し，欠陷周辺の電磁場が乱される。この現象をサーチコイル で測定することにより，陷の深さおよび形状を同定すること ができる，ECT では，高周波励磁を行うほど，表皮効果によ り，渦電流が金属構造物の表面近傍を流れるため，配管などの 内側の傷を测定するには，配管内部で測定装置を使わなければ ならず，小さな配管や複雑な構造物に適用するには容易ではな W.

本論文では，ECT による金属構造物の裏側欠宿探傷を試み た．董側欠陥を推定するには，渦電流が金属構造物の深部まで 浸透するように励磁電流周波数を低くすればよい，しかし，周 波数を低くすると，表皮効果により，渦電流分布が板厚方向に 広がってしまうため，欠陥が存在するときと，しないときとで の渦電流変化量が小さくなり, その結果, サーチコイルが検知 する誘導起電力の変化量も小さくなるので, 裏側欠宿を同定す ることが困難となる．このため，著者らは，サイン波励磁とコ
サイン波励磁を組み合わせることによって, 被探傷物に移動磁 場を印加し，裏側欠陷の同定を試みた，通常の交番磁場では， 被探傷物中の磁場は，時間的に增減を絽返すのみであるが，移 動磁場を印加することによって，被探傷物中の磁場をべクトル 量として変化されることができる．したがって，畑検出に対 して，より感度の高い磁場を印加することとなる. 本論文では, 我々が新たに開発した移動磁界型磁気探傷装置の構成を示し， 本装置による裹側欠陥の探傷結果について報告する.

\section{2. 実験方法}

Fig. 1(a), (b) に示すようにサイン波励磁を行うためのコイル とコサイン波励磁を行うためのコイルを, 交互に配置すること によって移動磁界を発生するための励磁コイルを構成する. 泑 磁コイルには, $\phi 0.5 \mathrm{~mm}$ 銅線 100 ターンを一巻きとし, Fig. 1 に示すように， 3 組みで 1 相分を構成している. 各相の各コイ ルは並列に接続されている.

测定システムを Fig. 2 に示す. D/A コンバータとバイポー ラ型パワーアンプを介して励磁コイルに励磁電圧を供給し，

被探傷物に移動磁界を印加する.H-コイル（以下, サーチコ イルとする) からの電圧は, 直流堌幅器で増幅した後, $\mathrm{S} / \mathrm{H}$ (Sample Hold) ュニット, A/D コンバータによりコンピュータ に取り込む. ここで, S/H ユニットは, 複数のサーチコイルで, 複数成分の磁束变化を検出する際に, 同一時刻の波形を得るた めに，サンプル波形をホールドするために用いる. 取り込んだ

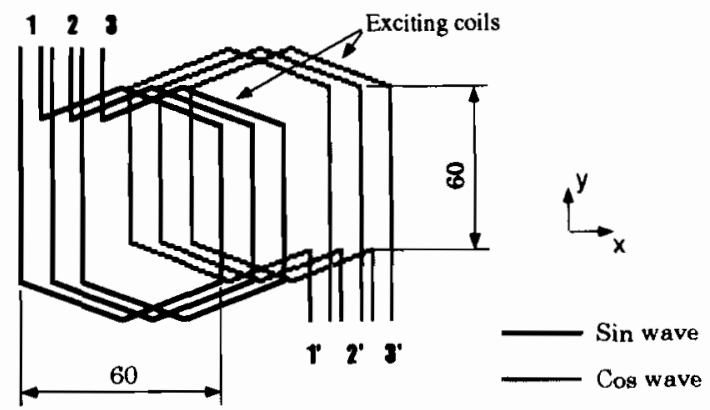

(a) Arrangement of exciting coils

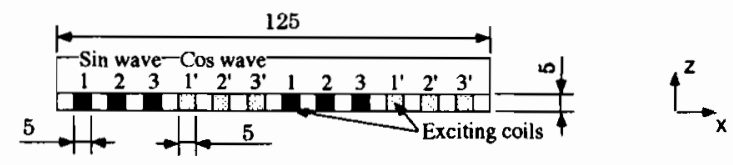

(b) Cross-section of exciting coils

Fig. 1 Exciting coils (units in millimeters). 
データはコンピュータにより波形処理を行う。この際, 測定結 果に測定装置系のノイズが見られるため，8周期分のデータを 取り込み，同期平均を行ってノイズを低減した．Fig. 2 に示す ように，サーチコイルと励磁コイルは，移動板（アクリル板） を介して自動座標测定装置に取り付けてあり、コンピュータ制 御により，精密に位置を決定している。また，Fig. 3 に示すよ うに, サーチコイルは，励磁コイルとともに移動板に取り付け られておら，同時に非探傷物上に移動する．移動した各点にお いて, 被探傷物に移動磁界を印加し, 渦電流の変化を湘定する.

被探傷物之しては，Fig. 3 に示すように, $200 \mathrm{~mm} \times 100$ $\mathrm{mm} \times 5 \mathrm{~mm}$ 鋼板（軟鉄, SS41）の中央部に人工的に裹側欠楩 を作成したものを用いた，裹側欠陥の幅が，0.4 mm, $0.6 \mathrm{~mm}$, $1.0 \mathrm{~mm}$ あのに対して, それぞれ, 久陥深さが $4 \mathrm{~mm}, 3 \mathrm{~mm}, 2$ $\mathrm{mm}, 1 \mathrm{~mm}$ の鋼板, 無欠陌の鋼板および, 溶接を施した鋼板の 14 種類の鋼板について测定を行った.

湘定点は，Fig. 4 に示すように, 久陥があるが鋼板の中央部

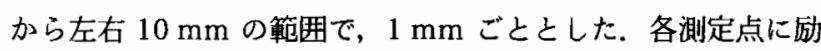
磁コイルの $x-y$ 平面での中心点（サーチコイルの中心点も同一 点)を一致されて測定を行った。

サーチコイルの形状・寸法については, Fig. 5(a)〜(d) に示す 4 種類で検討を行った. Fig. 5 に示すように, 各サーチコイル を Туре-1〜4 コイルとする. サーチコイルは $0.4 \mathrm{~mm}$ 厚アク リル平板に, Type-1, 2 は $\phi 0.14 \mathrm{~mm}$ 銅線を, Type-3, 4 は $\phi 0.04$ ウメット線を巻いて作成した。サーチコイル厚のた め，各コイルを用いたときのりフトオフ（励磁コイルと被探傷 物との間隔) は, それぞれ, $3.0 \mathrm{~mm}, 2.5 \mathrm{~mm}, 2.0 \mathrm{~mm}, 2.0 \mathrm{~mm}$ となる. Type-1, 3 のコイルには $x$ 方向の磁束変化を測定する $\mathrm{H}_{x}$-coil, $y$ 万向の磁束変化を測定する $\mathrm{H}_{y}$-coil が取り付けられて いるが, 今回の被探傷物では, 裏側欠陥が $y$ 方向に一様であり, $y$ 方向の磁束変化が微小であるので, Type-2, 4 では, $x$ 方向の 磁束变化を測定する $\mathrm{H}_{x}$-coil のみとし, Type-1, 3 においても, $x$ 方向磁束変化のみを測定した．各サーチコイルの有効エリア ターンは, 標準コイルを用いて测定を行い, それぞれ， 0.015664, 0.004958,0.00196,0.0011975 Turn·的である.

Type-1〜3のサーチコイルについでは，前述したように，励研 コイルの下部中心点に取り付け, Type-4については, 同一 $x$ $y$ 平面上, 中央点加らずれた位置 (Fig. 3 において， $x$ 方向に $62.5 \mathrm{~mm}$ 平行移動した位置) に取り付けた.

測定条件としては， $0.4 \mathrm{~A}, 10 \mathrm{~Hz}$ の励磁電流を用いた。

\section{3. 実験結果および考察}

\section{1 サーチコイルについての検討}

Fig. 5 に示した各サーチコイルを用いた湘定結果を，それぞ れ Fig. 6(a) (d) に示す. 裹侧欠陥幅については, $0.4 \mathrm{~mm}, 0.6$ $\mathrm{mm}, 1.0 \mathrm{~mm}$ にて测定を行ったが，これらの範井では，测定結 果には，ほとんど影響しないので，以後，探傷が最も困難であ る欠陷幅 $0.4 \mathrm{~mm}$ における結果のみ報告する.

Type-1 コイルでは，裹側欠宿がある鋼板と，無欠陥の鋼板 との区別は可能であるが，陌がある場合においても，全体と して起伏が䌅やかであり，欠陥の位置までを決定するに至って いない.

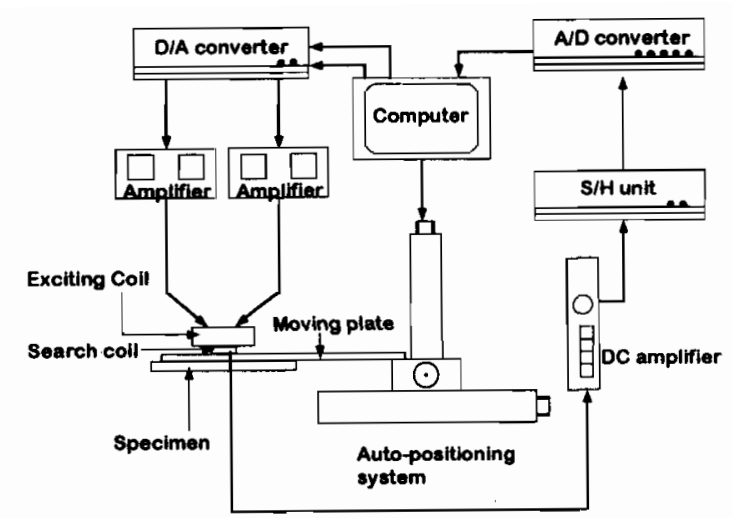

Fig. 2 Measurement system.

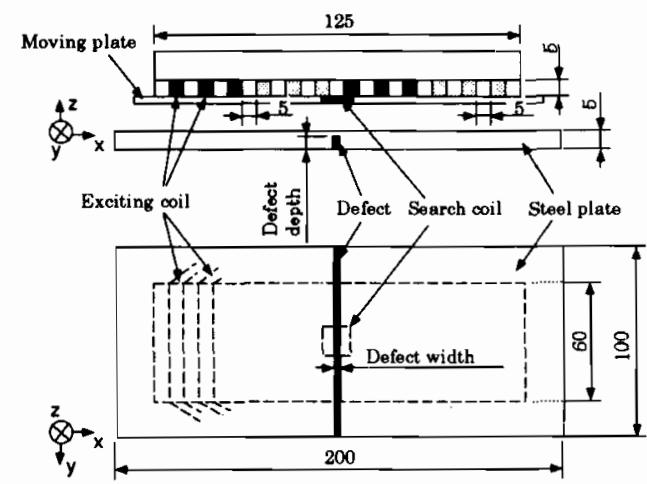

Fig. 3 Arrangement of exciting coils, the search coil, and the steel plate (units in millimeters).

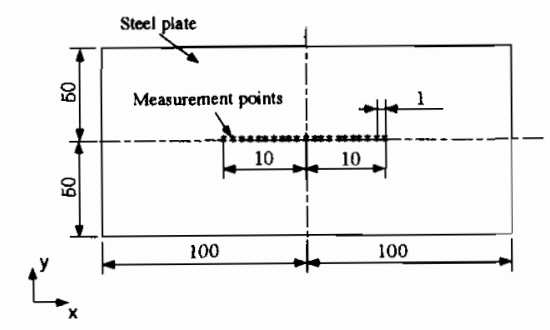

Fig. 4 Measurement points (units in millimeters).

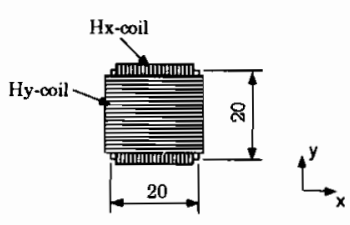

(a) Type-1 coil

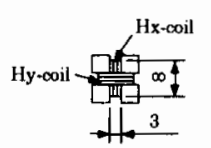

(c) Type-3 coil

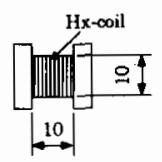

(b) Type-2 coil Hx-coil

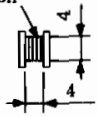

(d) Type-4 coil
Fig. 5 Searching coils (units in millimeters).

Type-2 コイルでは, 裏側欠陌がある中央部で若干の起伏が あり，裹側欠陷が起伏の頂点付近にあることが推定できる.

さらに, Ty pe-3 のコイルでは, 裹側欠陥が存在する中央部 で起状が激しく, 欠陷の存在とその位置を同定することが可能 である. Type-3に比べて, Type-1,2における結果の起伏が緩 やかであるのは, Type-1,2 コイルでは, 久陷幅に対して, コイ ル自身の大きさが大きいために，サーチコイルが久宿付近の広 


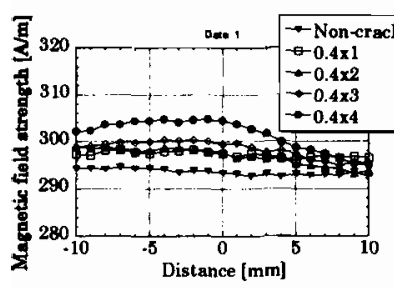

(a) Type-1 coil

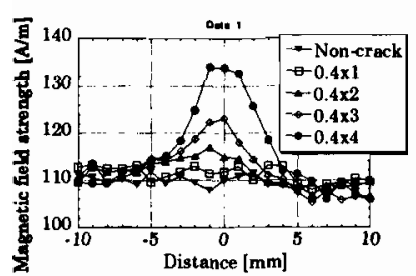

(c) Type-3 coil (b) Type- 2 coil

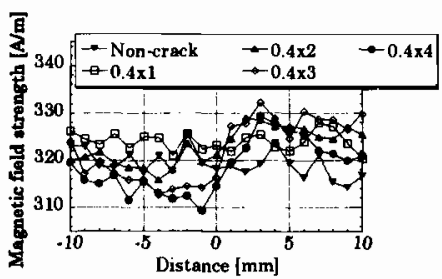

(d) Type- 4 coil

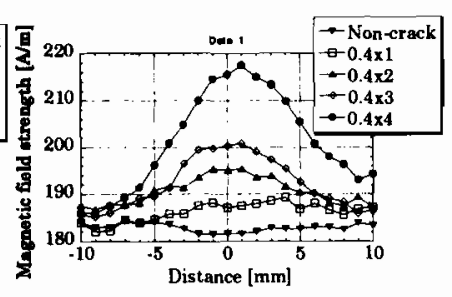

Fig. 6 Effects of searching coils.

範囲における磁束を拾ってしまい，裏側欠宿の存在による磁束 の変化が，他の磁束によって鈍化されてしまうためであると考 えられる。

しかしながら，さらに寸法の小さい Type-4 コイルでは,

Fig. 6(d) に示すように欠宿の存在および位置は推定できない. これは本コイルが小さいために有効なエリアターンが小さくな り，牛陥により磁柬变化がノイズに埋もれてしまう結果である と考えられる。

以上の検討より，本被探傷物では，Type-3 コイルを用いて， 湘定を行うこととした．以上は表皮深さに影響されるために， 被探傷物の板厚が異なれば，再検討する必要がある。

\section{2 衰㑡欠陷の推定}

Type-3 コイルを用いた場合の結果を Fig. 7, Fig. 8(a)〜(c)に 示す.

無欠陷鋼板と溶接した鋼板の場合の測定結果を Fig. 7 に示 す.溶接した銅板と無欠俩鋼板では明らかにセンサーコイルに よる出力が異なることがわかる。

Fig. 8(a) (c) は, 欠陥幅 $0.4 \mathrm{~mm}$, 欠陥深さが 1, 2,3,4 mm の轰側欠陥を有する鋼板について，励磁周波数を $10 \mathrm{~Hz}, 20$ $\mathrm{Hz}, 40 \mathrm{~Hz}$ で測定した場合の結果である. $10 \mathrm{~Hz}$ 時では，久宿 深さ $4 \mathrm{~mm}, 3 \mathrm{~mm}$ の裏側久陥については同定可能であるが, 2 $\mathrm{mm}$ の欠陥は, 同定が困難であり，佰深さ $2 \mathrm{~mm}$ において無 欠宿鋼板とほとんど区別がつかなくなっている，20 Hz, $40 \mathrm{~Hz}$ 之周波数を上げていくと，欠陥深さが梁いあのでは，欠陥があ る位置での出力の起伏が激しくなり，欠陷の位置はわかりやす くなるが, 周波数が大きくなるにつれて, 表皮深さが浅くなり， 渦電流が鍶板表面に集中してくるので，同定可能な裹側欠宿の 深さが浅くなり，両周波数で欠陥 $4 \mathrm{~mm}, 3 \mathrm{~mm}$ 深さしか同定 できない.

\section{3 サーチコイルの高性能化}

まず，Fig. 9 に示すように，内部に磁性線 (Fe-6.26\% Si, $\phi 69$ $\mu \mathrm{m})$ を入れたサーチコイルを作成した。これは，サ・チコイル 内部の磁束密度を大きくすることで，裏側欠陥に対する磁束変 化の感度をよくするためである．本サーチコイルを Type-5 コ イルとする. Fig. 9 に示すように, 磁性線は $x$ 方向にのみ施し

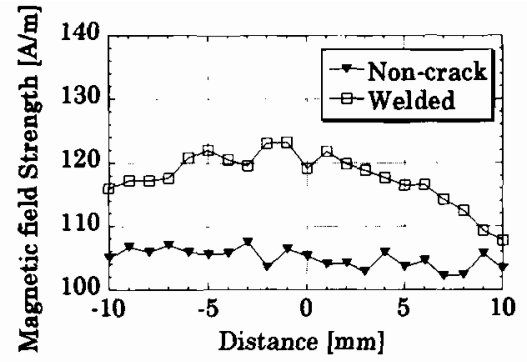

Fig. 7 Magnetic field strength picked up by a type-3 coil.

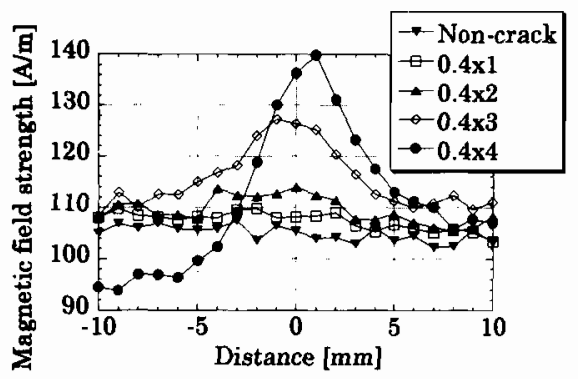

(a) Exciting frequency: $10 \mathrm{~Hz}$

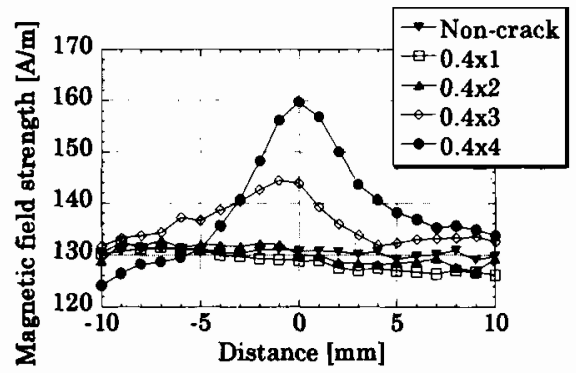

(b) Exciting frequency: $20 \mathrm{~Hz}$

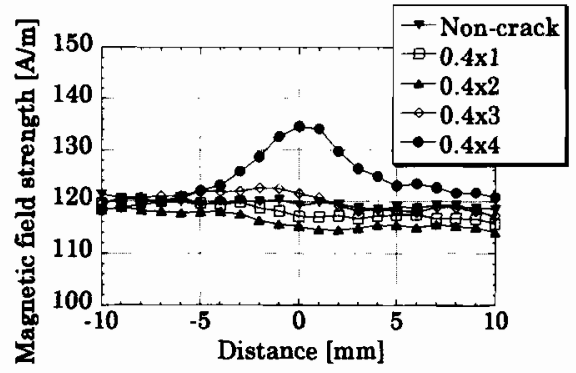

(c) Exciting frequency: $40 \mathrm{~Hz}$

Fig. 8 Effects of frequencies by a type-3 coil.

た. 前節でも言及したように, 本被探傷物では, $x$ 方向以外の磁 束変化が微小であるからである，なお，Fig. 9 では，中央左側 のみコイルがあるが，実際は全体に巻いてある，本サーチコイ ルによる測定結果を Fig. 10(a), (b) に示す. Fig. 10(a), (b) は, それぞれ励磁周波数が $10 \mathrm{~Hz}, 20 \mathrm{~Hz}$ の場合である。前項の測 定では, $10 \mathrm{~Hz}$ 時には久宿深さ $2 \mathrm{~mm}$ の同定は困難であった が，本サーチコイルを用いた測定では， $2 \mathrm{~mm}$ 欠宿です明確に 起伏が得られることがわかる，20 Hz 時においても，欠俩深さ $4 \mathrm{~mm}, 3 \mathrm{~mm}$ での感度は最も良いことがわかる。

次に, Fig. 11 に示すサーチコイルを用いた. 本サーチコイル を Type-6 とする. Type-5 のサーチコイルと同一の磁性線を 内部に施し，亭側欠陥に上る磁束の変化を，広範囲で測定でき 


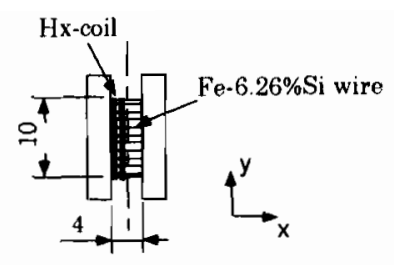

Fig. 9 Type-5 coil $\mathrm{Fe}-6.26 \% \mathrm{Si}$ wires (units in millimeters).

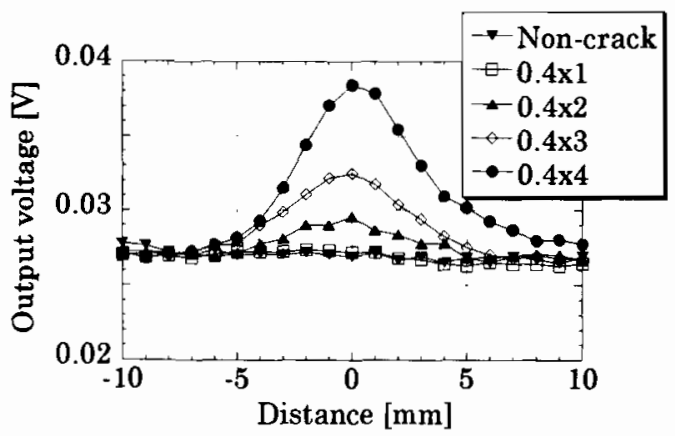

(a) Exciting frequency: $10 \mathrm{~Hz}$

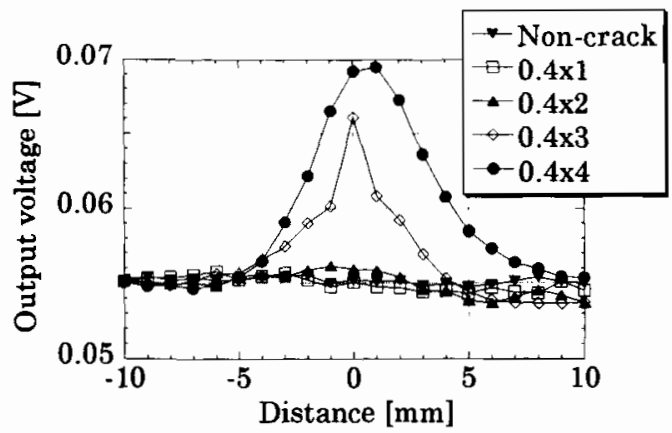

(b) Exciting frequency: $20 \mathrm{~Hz}$

Fig. 10 Effects of frequencies by a type- 5 coil.

るように，コイルの巻き線を久陷に対して斜め 45 度にした。 測定結果を Fig. 12(a), (b) に示す．そ狆ぞれ，励磁周波数が 10 $\mathrm{Hz}, 20 \mathrm{~Hz}$ の場合の測定結果である. Type-1〜5のサーチコイ ルによる測定結果のいずれと比較しても，你深さ $2 \mathrm{~mm}$ ま で，容易に同定することができる。しかしながら，本っイルを 用いても，准深さ $1 \mathrm{~mm}$ の同定は不可能であった。

\section{4. まと め}

$200 \mathrm{~mm} \times 100 \mathrm{~mm} \times 5 \mathrm{~mm}$ 鋼板（軟鉄, SS41）に対して, 裏側に施した深さ, $1 \mathrm{~mm}, 2 \mathrm{~mm}, 3 \mathrm{~mm}, 4 \mathrm{~mm}$ の欠陥の同定 を、新しく開発した移動磁界型磁気探偒装置を用いて行った. サーチコイルの改良を行うことによって，欠陷深さ $4 \mathrm{~mm}, 3$ $\mathrm{mm}, 2 \mathrm{~mm}$ の裏側久陷まで同定することが可能となった。さう

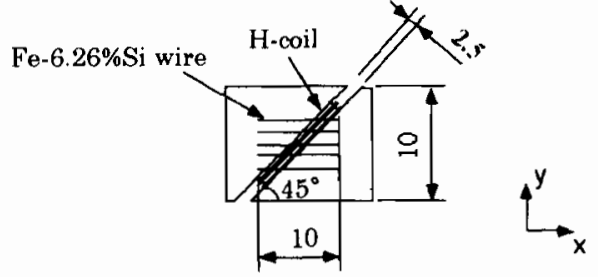

Fig. 11 Type-6 coils with $\mathrm{Fe}-6.26 \% \mathrm{Si}$ wires (units in millimeters).

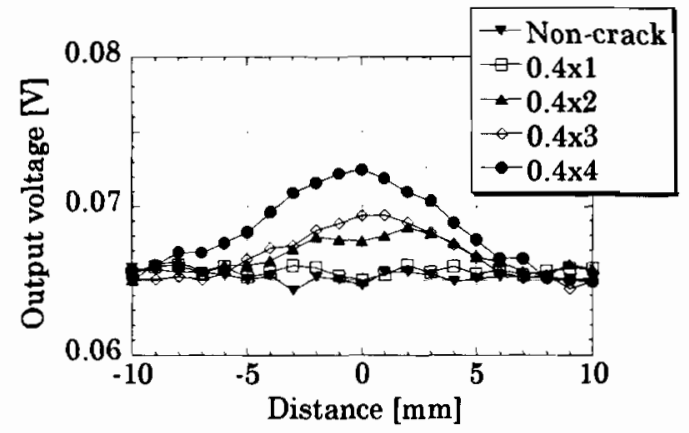

(a) Exciting frequency: $10 \mathrm{~Hz}$

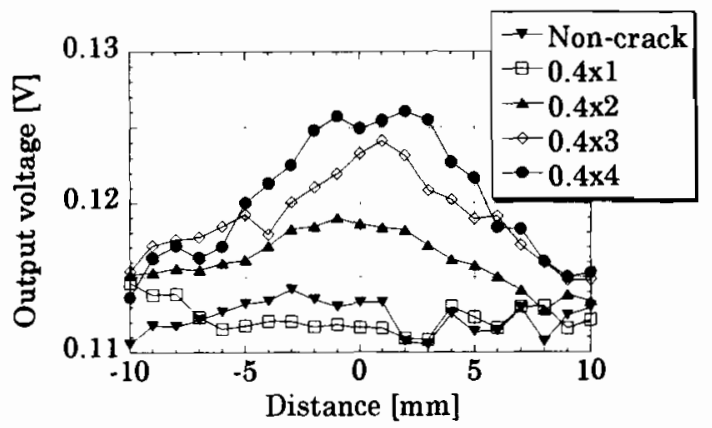

(b) Exciting frequency: $20 \mathrm{~Hz}$

Fig. 12 Effects of frequencies by a type- 6 coil.

に，より信頼性の高い非破壊検查装置とするためには，サーチ コイルおよび励磁コイルの改良が望まれる。

\section{文献}

1) K. Hakuta et al: Proc. ESAEM 6, Advanced Computational and Design Techniques in Applied Electromagnetic Systems, ed. by S. Y. Hahn, Seoul, 1994, p. 157 (Elsevier, Amsterdam, 1995).

2) S. Nagata and M. Enokizono: Proc. ESAEM 6, Advanced Computational and Design Techniques in Applied Electromagnetic Systems, ed. by S. Y. Hahn, Seoul, 1994, p. 141 (Elsevier, Amsterdam, 1995).

1996 年 10 月 16 日受理, 1997 年 1 月 16 日採録 